\title{
EL MOVIMIENTO MAPUCHE Y LA PRIMAVERA CHILENA
}

Tito Tricot ${ }^{176}$

\section{Introducción}

La primavera constituye un ciclo vital de la naturaleza, que se repite año a año, en un ciclo circular. La historia, por su parte, aunque es probable que no sea circular, o que vuelva cada cierto tiempo a su punto de partida en un ciclo interminable, de tanto en tanto nos asombra con singulares coincidencias. Por ello — quizás- es que los noviembres de Chile y Wallmapu se incrustan en las primaveras con la violencia de la historia política de estos países, primaveras que sabemos cuándo empezaron, más no podemos presagiar cuándo culminarán. Precisamente, porque los noviembres parecieran repetirse.

Alex Lemun, joven mapuche de tan solo 17 años, de la comunidad Requem Lemun de Ercilla, fue asesinado de un balazo en la cabeza en noviembre de 2002 por el mayor de Carabineros Marco Aurelio Treuer. A Gustavo Gatica, estudiante de psicología de la Universidad de Academia de Humanismo Cristiano, le arrancaron sus ojos el 8 de noviembre de 2019 en la Plaza Dignidad de Santiago. Fueron carabineros de las Fuerzas Especiales. En Wallmapu, en la comunidad de Temucuicui, fue asesinado por la espalda y con un disparo en la nuca el joven comunero Camilo Catrillanca. Ocurrió el 14 de noviembre de 2018. El responsable fue el sargento de Carabineros Carlos Alarcón, integrante del denominado Comando Jungla ${ }^{177}$. Carabineros, también de Fuerzas Especiales,

170 El Comando Jungla fue una Unidad Especial de Carabineros de Chile con entrenamiento en Colombia. Estaba destinada a efectuar operaciones represivas en territorio mapuche. 
dispararon directamente y a corta distancia, a la cabeza de Vicente Muñoz, estudiante de teatro de la Universidad de Chile de 19 años, destrozándole un ojo. Fue el 11 de noviembre del 2019 en la Plaza Dignidad.

Cuatro noviembres, tres primaveras, una sola historia, pues esta última no es que se repita, sino que está engarzada por dos elementos concomitantes: la violencia política y la represión a los movimientos sociales. Ambos configuran un sistema de poder que no reconoce fronteras étnicas, culturales, identitarias, nemónicas o nacionales cuando se trata de preservar esta matriz socio-política y económica. Es una constante que se ha verificado a través del tiempo desde la génesis del Estado-Nación chileno, el cual surgió por la violencia y se desarrolló y consolidó mediante esta. En lo concerniente al Pueblo Mapuche, esto se ha materializado en un continuum histórico de dominación ${ }^{178}$ engarzado por dos negaciones: la negación originaria, que culminó en el siglo XIX con la ocupación militar del territorio mapuche, y la segunda negación, plasmada en el siglo XX, con la implementación del modelo neoliberal y el desarrollo de la industria forestal y extractivista. En ambos casos — que no se pueden analizar ni comprender como fenómenos aislados - se ha intentado asimilar o aniquilar al Pueblo Mapuche física, cultural o socialmente. En lo referente a los movimientos sociales chilenos, principalmente -aunque no exclusivamente- de obreros, campesinos y pobladores, se han producido innúmeras matanzas en casi todos los gobiernos. Si uno se remite solo al siglo pasado, pareciera que los millares de muertos y heridos fueran la resultante de una política pública de Estado. Si no, ¿cómo se explican las masacres de la huelga portuaria en Valparaíso (1903); huelga de ferrocarriles en Antofagasta (1906); escuela Santa María de Iquique (1907); Federación Obrera de Magallanes, Punta Arenas (1920); La Coruña, Tarapacá (1925); Ranquil, Malleco (1934); población José María Caro (1962); El Salvador (1966); Puerto Montt (1969); Laja (1973); Pisagua (1973); Lonquén (1973); y, Operación Albania (1987), entre otras ${ }^{179}$ ? Y actualmente, en el siglo XXI, en el marco del Estallido Social, se contabilizan, al menos, una treintena de muertos y 450 personas a quienes les han mutilado sus ojos. Además de miles de heridos, torturados y hombres y mujeres abusadas sexualmente. Entonces, no es la historia que se reitera, sino que es, simplemente, la historia.

Puede habernos sorprendido el Estallido y el movimiento social, pero no la violencia del poder. Obviamente la violencia política no siempre es ostensible ni se recurre a ella de manera permanente. Lo que se ejerce es el poder. La violencia es racionalizada, administrada e instrumentalizada, componente de una arquitectura de poder cuyo objetivo final no es solo la represión, ni el terror, ni la tortura, ni la muerte, sino, principalmente, el control social. En el caso específico del Estallido Social y del Movimiento Mapuche: control social y control colonial.

Es en el contexto de lo precedentemente expuesto, que este artículo busca analizar el tipo de vínculo que pudiera existir entre la llamada Primavera Chilena, es decir, el Esta

171 Para un detallado análisis de este abordaje teórico ver Tricot, T. (2013).

172 No se incluyen, por cierto, los miles de heridos en estas mismas matanzas ni los millares de heridos en protestas de décadas de movilizaciones sociales. 
llido y movimiento social ${ }^{180}$, y el Movimiento Mapuche. Para intentar lograrlo, el análisis se realizará en dos dimensiones principales. En primer lugar, desde el ángulo del poder, fundamentalmente aquello que remite a los dispositivos utilizados para la preservación del modelo neoliberal, y más exactamente, lo que refiere a la elaboración de un discurso central militarista y a su correlato práctico. También a la faceta política institucional que se engasta con el discurso y la acción colectiva para constituir una totalidad. Lo anterior, siempre en relación directa con los movimientos sociales. En segundo lugar, busca abordar la plausible vinculación entre el movimiento social chileno y el Movimiento Mapuche, aproximándose a dicho análisis desde el prisma del contra-poder.

El Movimiento Mapuche es de antigua data, no así, evidentemente, el movimiento chileno social actual, por tanto, las interrelaciones, símiles, diferencias, repertorios de acciones, simbologías, discursos, continuidades y rupturas, mitos, leyendas y memorias individuales y colectivas, entre otros elementos movimentales, son todas susceptibles de ulteriores profundizaciones. Sin embargo, ello no obsta para examinar el eje de contra- poder desde la conexión Movimiento Mapuche y Estado-Nación chileno y, también, movimiento social y Estado-Nación chileno. Ambos, en el marco de la estructuración de un modelo neoliberal.

\section{No son 30 pesos ni 30 años, son 140 años}

La consigna "No son 30 pesos, son 30 años", una de las tantas surgidas durante el Estallido Social y posterior movimiento desde el 18 de octubre de 2019, alude al incremento de la tarifa del Metro de Santiago que, simbólica y factualmente, se sitúa como el inicio de esta Primavera. También podría signarse como el término, al menos transitorio, de un luengo invierno histórico. Pero, también, alude a la consolidación del modelo neoliberal impuesto por la dictadura cívico-militar en la década del setenta por parte de los gobiernos de la Concertación, la Nueva Mayoría y la Derecha.

¿Por qué hablo de 140 años en el título de esta sección? Porque ése es el lapso transcurrido desde la invasión definitiva del país mapuche por el ejército chileno en 1883. Lo de las cifras no es meramente una cuantificación caprichosa ni un slogan, o únicamente un grito de legítima furia, sino que devela - como se ha sostenido - la continuidad de los procesos históricos en un anclaje estructural específico y la expresión más concreta, en la actualidad, de la apropiación por desposesión capitalista y endocolonial, a través de un prolongado periodo de implementación de un modelo de desarrollo neoliberal. Este no consiste exclusivamente en una teoría, paradigma o estrategia económica, sino que articula una serie de dispositivos, mecanismos, valores, lenguajes, narrativas, códigos y prácticas de control social. El modelo se apropia de todas las dimensiones del espacio social: económico, cultural, político, ideológico, individual, colectivo, privado y público. Mercantiliza las relaciones sociales mientras el mercado reemplaza - hasta cierto punto- el ejercicio de la ciudadanía, diluyendo dicho valor y práctica en el propio consumo. De

173 No es el objetivo de este artículo debatir en profundidad acerca del carácter del Estallido y movimiento, admitiendo que coexisten distintas versiones y abordajes en torno al fenómeno. Las hay también en relación al concepto mismo de movimiento social. 
esta forma, se evapora la política para reducirla al mínimo procedimental expresado en votaciones periódicas, cada vez más simbólicas, cada cierto tiempo. Pero, para la minoría dominante -aquella que agencia el modelo- ni el poder, ni la política, ni la violencia están vacías de contenido, no son neutrales, pues el contenido de la política no es la política per se, aunque se despliegue en el campo de lo que convencionalmente se nombre como la institucionalidad, sino que carga con un peso económico del cual nunca puede desprenderse. Menos aún de su lastre de pobreza y desigualdad, que son las grandes esferas que ocluyen el derecho a la vida, pero no para todos. Simplemente, porque este modelo produce pobreza para que otros puedan ser ricos, o riqueza para que otros sean pobres.

En Chile el sueldo promedio es de 481 mil pesos, las pensiones promedio ascienden a 157 mil pesos, el $50 \%$ de los hogares de menores ingresos accede al 2,1\% de la riqueza del país, mientras que el $10 \%$ más rico se queda con el 66,5\%. Además, 140 personas en Chile concentran, cada una, una fortuna mayor a 100 millones de dólares. ¿Quiénes son los más ricos? Julio Ponce Lerou, con 3.800 millones de dólares; Horst Paulmann, con

3.000 millones de dólares y, por supuesto, el presidente Sebastián Piñera, con una fortuna de 2.800 millones de dólares. Privilegios que, sin duda, son necesarios de proteger recurriendo a la arqueología del saber. Quizás por eso es que el presidente Sebastián Piñera (2019) declaró estar "en guerra contra un enemigo poderoso, implacable, que no respeta a nada ni a nadie y que está dispuesto a usar la violencia y la delincuencia sin ningún límite, incluso cuando significa la pérdida de vidas humanas, con el único propósito de producir el mayor daño posible". En otras palabras, exhumó el antiguo y conocido aforismo de que "la guerra no constituye simplemente un acto político, sino un verdadero instrumento político, una continuación de la actividad política, una realización de ésta por otros medios" (Clausewitz, 2002:19). En su discurso y acción tomó su verdadero sentido disciplinador y aniquilador, porque la violencia política está siempre presente en la política, es en sí misma política, siendo la guerra una forma aguda de la misma.

La dictadura cívico-militar del general Pinochet definió a un enemigo interno ${ }^{181}$ para una guerra imaginaria, construyendo un discurso que sustentara ideológica y políticamente dicha entelequia. El presente Gobierno ha hecho exactamente lo mismo, criminalizando al movimiento social de la misma manera que se ha estigmatizado al Movimiento Mapuche. Dos movimientos sociales que se han soliviantado para desnudar los abusos de un sistema institucionalizado y constitucionalizado. Incluso, es dable decir que un porcentaje significativo de la población, consciente o inconscientemente, lo aceptó, o al menos internalizó valores, actitudes y prácticas individualistas e insolidarias, siendo funcionales al neoliberalismo que promovía una cultura aspiracional. Para algunos pocos, el ascenso social fue limitadamente real, implicó mejores condiciones de vida material — casa propia, automóviles, electrodomésticos-vía endeudamiento. En otras palabras, pobres a plazo. Mientras los ricos de verdad, a costa de los pobres de verdad y de los pobres a plazo, continuaban acumulando riquezas. Hasta que Chile despertó un día viernes 18 de octubre.

174 La doctrina de la seguridad nacional ideada por militares brasileños estadounidenses transformó al enemigo externo (hipotéticos países enemigos) por un enemigo interno. Estos fueron, superpuestamente, los comunistas, marxistas y subversivos pero, en los hechos, lo fue cualquiera que se opusiera a las dictaduras cívico-militares. Las consecuencias fueron horrorosas: miles de asesinados, desaparecidos, torturados, detenidos y exiliados. 
Con todo, es erróneo pensar que con anterioridad a la emergencia de este Estallido los chilenos hubiesen estado sumidos en un extenso letargo movimental desde el retorno a la democracia, a pesar de lo que se ha tildado como el conjuro de los movimientos sociales y el evidente disciplinamiento de estos por parte de los primeros gobiernos de La Concertación (Guerrero, 1997). El Puertazo en Valparaíso, donde en la década del 90 toda la cuidad se movilizó en la defensa del puerto y los importantes movimientos - en distintos momentos y con diversas demandas - como el de Aysén, feminista, estudiantil, de profesores, subcontratistas, de la salud, pingüinos, portuarios, pescadores artesanales de Chiloé, Pascua Lama, contra la Hidroeléctrica en la Patagonia y contra el megaproyecto minero Dominga en La Higuera, por mencionar algunos, atestiguan que se desarrolló una reconstitución de un sujeto social probablemente diferente a los clásicos, en línea con el surgido producto del Estadillo social. Todos fueron objeto de violencia desde el poder, tal como el Movimiento Mapuche. Es decir, es posible argumentar que tanto el movimiento social presente y el Movimiento Mapuche están unidos por la violencia estatal. Existe una vinculación externa definida por una guerra ficticia interna, puesto que se ha demarcado un enemigo también interno. Histórica y sistemáticamente se ha reprimido, pero particularmente, desde los eventos de Lumako, en 1997, aun cuando no se puede hacer una dicotomía entre los procesos sociales del Movimiento Mapuche Autonomista. Ahora,

el pueblo chileno movilizado vivenció lo que ha pasado los últimos 30 años en

Wallmapu. Fue una experiencia traumática para todas las fuerzas sociales que salieron a las calles entre octubre de 2019 y febrero de 2020. Es triste compartir hechos que son repudiables, pero creo que también aquello nos permitirá indignarnos más y seguir movilizados. Aún nada ha cambiado, falta mucho y debemos seguir luchando. (Antileo, 2020, entrevista personal)

La violencia exógena o estructural es la peor de las violencias porque es institucional y se ejecuta dentro de un marco legal. Es la peor pues, aparentemente, es legítima, moral y normativamente aceptable por la sociedad que ha depositado en el Estado la salvaguarda del orden público. Fundamentado en el supuesto de la representación del bien común, el Estado ha elaborado una sofisticada, aunque paradójicamente fútil narrativa, criminalizando al Movimiento Mapuche, adscribiéndole un carácter terrorista, donde la idea clave la verbaliza el presidente Sebastián Piñera, y es que

en la Región de La Araucanía sí hay terrorismo, y los que lo quieran negar están tratando de tapar el sol con un dedo, porque cuando se comenten los actos que hemos conocido, naturalmente que hay en eso un acto de terrorismo. Y, por eso, hemos aplicado la Ley de Seguridad del Estado, cuando corresponde, la Ley Antiterrorista, cuando corresponde, y lo vamos a seguir aplicando ${ }^{182}$.

Esta afirmación se efectuó en la ciudad de Temuco, en el corazón del territorio mapuche, a solo tres meses del asesinato de Camilo Catrillanca acaecido en Temucuicui. Esto puede tener la siguiente lectura: la violencia estructural no es sencillamente una narrativa, sino que es intrínseca al EstadoNación, un componente sedimentado de prácticas políticas e ideológicas que construyen acciones concretas. ¿Por qué? Porque la visita que hizo el ministro Chadwick al territorio también puede ser

175 https://www.eldesconcierto.cl/2019/02/21/pinera-insiste-en-que-hay-terrorismo-en-la-araucania-los-que-lo-quieran- negarestan-tratando-de-tapar-el-sol-con-un-dedo/ 
considerada un respaldo del presidente al accionar represivo durante y A posteriori al asesinato de Camilo Catrillanca. Carabineros mintió en relación a su muerte y tanto el ministro como el subsecretario Rodrigo Ubilla repitieron la versión policial de que el comunero había atacado a balazos a Carabineros. En síntesis, una vez más, se legitimaba la violencia estructural. No tan solo eso, un mes antes, ya Chadwick viajó a Temuco sabiendo que se había realizado un montaje ${ }^{183}$ no para disculparse ante la familia de Camilo, la comunidad de Temucuicui o el Pueblo Mapuche, sino que para reunirse con empresarios y agricultores de la zona, expresando diáfanamente que

nuestra prioridad de hoy es lo que el Presidente de La República nos ha señalado, de decirle a estas víctimas de la violencia que no están solas, que vamos ahacer todo lo que esté a nuestro alcance para los efectos de poderles colaborar, a mitigar el dolor y el daño que han sufrido con la violencia que se ha producido, y a entregar lo antes posible los beneficios que como Estado de Chile se han aprobado para ellos ${ }^{184}$.

Se trastocan las violencias, las subjetividades, los dolores, las muertes y las vidas. En un macabro juego de espejos se ocultan la discriminación, la asimilación, la usurpación territorial, la criminalización social y política. No se asume responsabilidad política, porque la protección del modelo forestal y extractivista lo imposibilita, porque la reproducción del sistema en su conjunto lo requiere y, por sobre todo, debido a que la violencia política es parte constitutiva del modelo, el cual no es solo económico, como se ha sostenido. Para el Gobierno, lo acaecido en Temucuicui fue solo un problema administrativo a pesar que la Comisión Especial Investigadora de la Cámara de Diputados fue enfática y precisa en puntualizar que la muerte de Catrillanca

[...] no fue una decisión de los Carabineros que fueron dados de baja y se encuentran en proceso judicial, sino que fue una decisión tomada en el Palacio de La Moneda. Corresponde, entonces, al ministro del Interior, Andrés Chadwick, y al subsecretario Rodrigo Ubilla, la decisión política de las materias que tengan que ver con el orden público y la seguridad interior

$\mathrm{y}$, por lo tanto, asumir sus consecuencias ${ }^{185}$.

Nadie asumió las consecuencias políticas, más aun, el propio ministro Chadwick en declaración ante una sesión especial del Senado sobre la situación en La Araucanía, apenas un mes después del asesinato de Camilo Catrillanca, señaló que "es la policía que tiene el deber de cumplir con una misión indispensable: darnos seguridad en nuestras vidas... Por favor, ¡cuidemos a Carabineros!" (Chadwick, 2018). Al ex ministro Chadwick tampoco parece haberle importado la acusación constitucional aprobada por el Senado en diciembre de 2019 por haber infringido gravemente la Constitución y las leyes, y haber dejadode adoptar medidas para detener violaciones sistemáticas a los derechos humanos. No asumió su responsabilidad política y siempre respaldó el accionar de Carabineros pues, fue

\footnotetext{
176 Ante las denuncias de los mapuche y los medios de comunicación, Carabineros tuvo que reconocer su responsabilidad en el montaje y en el asesinato de Camilo Catrillanca. El gobierno tuvo que remover de su cargo a once funcionarios de Carabineros, entre ellos, dos generales, un coronel, un teniente coronel, un mayor y cinco suboficiales. Se les ha aceptado la renuncia y se les ha dado de baja por no haber respetado la ley ni los procedimientos.

177 https://www.elmostrador.cl/noticias/pais/2019/01/10/chadwick-no-descarta-aplicar-estado-de-excepcion-en-la-araucania/

178 https://www.camara.cl/prensa/sala_de_prensa_detalle.aspx?prmid=137968
} 
consecuente con su aserto de cuidar a Carabineros de Chile. Porque la violencia institucional está socialmente regulada y agenciada por personal del Estado, por ende, debería ser normativamente incontestable, salvo que llegase a ser ostensiblemente transgresora de estas mismas normas. Incluso, en tales casos, el castigo es mínimo, prohibición de ejercer cargos públicos o quizás, penas irrisorias de cárcel.

La palabra del poder utiliza el poder de la palabra para legitimar lo que hace y omitir sus crímenes. Por eso, uni-lateraliza el conflicto en territorio mapuche, nombrándolo como conflicto mapuche, reduciéndose su causa u origen a un actor político: el Pueblo Mapuche, adscribiéndosele, además, una cualidad terrorista al Movimiento Mapuche Autonomista. Del mismo modo, deslegitima al Estallido y movimiento social, primero minimizándolo, después denunciando presencia extranjera y, finalmente, acusándolo de violentista e intentándolo dividir entre aquellos sectores supuestamente pacíficos y otros violentos. Exactamente lo que han hecho con el Movimiento Mapuche. De manua introductorio. Nada, absolutamente nada, nuevo.

\section{Cuando se pierde el miedo... vamos por la doble autonomía}

El golpe me dio vuelta la cara...si no me alcanzo a cubrir algo, no sé cómo porque no vi nada, pierdo los dos ojos. Siento mucho dolor, como una mano de metal caliente que se te mete en los ojos y te los arranca. Corrí, corrí mucho rato, gritando, hasta que paré en un árbol. Llegó gente de

la brigada de Primeros Auxilios a ayudarme. Sentía sangre en la boca, la cara. Los pacos nos dispararon lacrimógenas mientras me curaban algo. (Muñoz, 2020, entrevista personal)

"iHay que cuidar a Carabineros! Para que lleven a cabo su labor de garantizar la vida”, dice el ex ministro Chadwick, pero Vicente Muñoz verá la vida solo a medias desde ahora en adelante. Gustavo Gatica no la verá más. Fabiola Campillay tampoco. Ella fue baleada también en uno de aquellos noviembres, que asoman como meses malditos, pero no en sí mismos, sino que maculados por una policía diseñada para reprimir. Los noviembres mapuche o, si se quiere, mapuche y chilenos, estarían unidos por la violencia del poder. Pedro Cayuqueo es claro en afirmar que

Los mapuche lo hemos sufrido desde los primeros años del retorno de la democracia y ha sido la tónica en gobiernos de centroizquierda y derecha, sin distinción. Hoy es el pueblo chileno el que sufre también la represión, el abuso policial y, es terrible decirlo, pero es otra de las consecuencias del Estallido Social; se democratizó en Chile el apaleo policial. Muertos, mutilados y heridos hemos tenido los mapuche desde los noventa, jóvenes activistas de comunidades acribillados a balazos, disparos de balines en el rostro, detenciones arbitrarias, secuestros y montajes policiales, la lista es larga y se viene denunciando hace décadas. Es lo

mismo que se ha visto en el Estallido Social de octubre, los mismos atropellos y la misma impunidad policial. Hoy a mapuche y chilenos también nos hermana, lamentablemente, el dolor que trae consigo la represión estatal. (Cayuqueo, 2020, entrevista personal) 
Sin embargo, también existe otro tipo de ligazón forjada entre el Estallido Social, el movimiento surgido a partir de este —o, para ser más exacto, aquel de las placas tectónicas que se venían desplazando ora imperceptiblemente ora episódicamente, en los últimos treinta años- y el Movimiento Mapuche. Este encadenamiento o vínculo no viene desde el poder, sino que desde el contra-poder, desde la resistencia "a un modelo neoliberal que privatiza la vida y también la muerte, y que tiene a nuestros territorios y sus recursos naturales convertidos en cotos de caza de las grandes transnacionales. En esta lucha estamos hermanados con el gran pueblo chileno, víctimas también de un sistema perverso y deshumanizante" (Cayuqueo, Op. cit.). Es la segunda dimensión, aquella que busca identificar las posibles interrelaciones movimentales en el presente periodo histórico, entendiendo que en el caso del Movimiento Mapuche Autonomista nos remite, al menos, a veinte años atrás, a los eventos de Lumako (Tricot, 2017, 2014, 2013, 2011; Pairican, 2014). Lumako, localidad en la provincia de Malleco donde se quemaron, en 1997, tres camiones de la forestal Bosques Arauco y se recuperaron los fundos Pichilinkoyan y Pililmapu, se transformó en un punto de inflexión en el desarrollo del Movimiento Mapuche Autonomista. Allí se materializó un giro movimental en el contexto general de un proceso de contraposición de ideas, tácticas, estrategias, liderazgos, modos de accionar y demandas de su acción colectiva. Lumako es depositario de muchos otros Lumako en la historia del Movimiento Mapuche y, sin duda, de otros futuros Lumako. La "mapuchización" del proceso reflexivo del movimiento había identificado al Estado y al modelo neoliberal como los actores principales enemigos de su pueblo. Se habían explorado e intentado todas las vías posibles para solucionar los problemas relativos a la usurpación de su territorio y sus tierras, y a la violencia por parte del Estado y las empresas forestales. Nadie los había escuchado, ni la institucionalidad ni los partidos, ni de centroizquierda ni de derecha. Era indispensable adoptar una forma distinta de organización y lucha que movilizara a las comunidades y, por sobre todo, que fortaleciera la confianza, la creencia en la fuerza propia y en que era posible un mañana mapuche. El Wallmapu había despertado, aunque, en rigor, nunca estuvo dormido.

Chile despertó mucho más tarde, pero despertó. Por la dislocación de las placas tectónicas de la conciencia, como argumentamos. Lumako fue un movimiento sísmico de gran magnitud, tanto por su accionar como por el giro autonomista de la demanda mapuche, o al menos, de un sector del movimiento. Las réplicas de aquel sismo se perciben hasta hoy, porque cambió la geografía y la geología conflictual, dibujándose una nueva cartografía que incluye ignotas constelaciones de sentido y de acción colectiva. Es aquí donde se establecen las similitudes y diferencias del Movimiento Mapuche Autonomista con el Estallido y movimiento social derivado de este. En el marco del conflicto chileno-mapuche se constató una doble autonomía: de los partidos políticos chilenos y del Estado y de su institucionalidad, con sus propias especificidades. Se puede sostener que lo mismo sucede con el movimiento presente. El prolongado cuestionamiento de los partidos, de la política convencional y de la mayoría de las instituciones públicas se había constituido en un elemento permanente del planisferio socio-político, no obstante, no se traducía en un movimiento social masivo, transversal y poderoso. Ello cambió radicalmente el 18 de octubre. En el sur, "el sentimiento de instrumentalización por parte de los partidos chilenos 
(había) motivado un fuerte proceso de autonomización de las organizaciones mapuches" (Tricot Víctor y Bidegain, 2020:7). Acá, además, fue la rabia acumulada por la relación en tre los políticos y el empresariado; la distancia entre los partidos y el ciudadano "común y corriente"; los altos sueldos de los parlamentarios; y la precariedad e inestabilidad en la que vive la mayoría de los chilenos. Simplemente nadie, o una minoría, cree en los par- tidos políticos y esto devino en una autonomización de los actores movilizados, que hoy creen en la fuerza propia al igual que los mapuche. Es decir, en una nueva forma de hacer política, sin los partidos.

Quizás se trata de la constitución embrionaria de un novel sujeto histórico, como lo es el Movimiento Mapuche Autonomista, que tuvo la capacidad de realizar un tránsito de reivindicaciones de tipo culturalistas y economicistas a otras de carácter políticas. Sea como fuere, este movimiento "marcará en muchos aspectos un antes y un después. Cualquiera sea su desenlace, las exigencias de la mayoría de la población no podrán ser negadas pura y simplemente como ocurría desde hace décadas" (Garcés, 2019:19). Este movimiento, al igual como dijimos en lo concerniente a Lumako, es depositario de muchos otros 18 de octubre y, seguramente, de otros futuros 18 de octubre por ser un punto de inflexión movimental en la historia de Chile.

La diferencia substancial con Lumako consiste en que, para el proceso de "mapuchiza- ción" del movimiento, el distanciamiento de los partidos políticos chilenos, generación de conciencia, organización de la fuerza propia y de creer en ellos mismos, fue crucial la labor de dirigentes y autoridades mapuche. En el caso del movimiento chileno, no existió dicho trabajo, independientemente que se haya dado a micro escala en algunos espacios y orga- nizaciones. No nos referimos a procesos históricos que, como se sostuvo antes, siempre son extensos y sinuosos, por consiguiente, el Estallido Social puede ser considerado parte constitutiva de tales procesos. Aludimos, específicamente a la estructuración y planifica- ción del Estallido mismo y a todas y cada una de las posteriores movilizaciones.

La otra expresión de la doble autonomía se desplegó en la confrontación con el Esta- do-Nación como instrumento articulador del modo de dominación. Este contra-poder rompía con esa matriz donde el Estado se erigía como el corazón de toda la musculatura de poder, copando todos los espacios públicos e incluso privados, excluyendo a la mayoría del proceso de toma de decisiones. Los mapuche, entre otras estrategias, optaron por la territorialización de sus demandas, la demanda por la recuperación del territorio histórico que les había sido usurpado por el Estado chileno y por colonos chilenos y extranjeros. El problema no se reducía solo a la tierra, sino que al territorio; no era económico, sino que político; no era la simple subsistencia en tanto campesinos - que no lo eran-, sino que la demanda por autonomía en tanto pueblo-nación. El territorio no es solamente un espacio geográfico, sino que un constructo social, un universo de significados culturalmente adscritos, habitado por la memoria, la identidad, el idioma, historias individuales y colectivas, mitos y organizaciones. La vida en su conjunto. Asimismo, es un espacio de disputas de poder.

Ese poder comenzó a disputar el Movimiento Mapuche Autonomista, y ahora el movimiento del 18 de octubre iniciaba un derrotero que, aparentemente, aunque de manera incipiente y con características básicamente urbanas y culturales diferentes, poseía rasgos 
similares. Esto último se asocia a lo territorial en el sentido de la emergencia y despliegue de innúmeras instancias organizativas ciudadanas auto-convocadas. Los cabildos se multiplicaron por todo el país, en Wallmapu también, replicando órganos de participación de origen colonial. Estos tuvieron carácter barrial, sectorial, comunal o alguna otra modalidad, dependiendo de sus convocantes. También variaron sus formas organizativas y objetivas, aunque denominadores comunes son la cualidad ciudadana, la auto-convocatoria, la exclusión de partidos políticos, la desideologización, la pluralidad, la transversalidad y el asambleísmo. Todo lo anterior se desplegó a nivel territorial, por eso, es dable plantear que, además de producirse una fractura con el poder del Estado, simultáneamente se materializó un naciente ejercicio de soberanía popular a través de la territorialización de un poder alternativo. Es preciso señalar, por cierto, que esto fue y es, limitado e incipiente, amén de muy complejo y diverso en sus expresiones. Por su breve tiempo de maduración, existe un gran abismo con el proceso llevado a cabo por el Movimiento Mapuche Autonomista, pero parece importante relevar el fenómeno, particularmente debido a que las asambleas territoriales son unas de las manifestaciones que es posible que perduren en el tiempo y trasciendan la duración de los cabildos que, en lo medular, devinieron en espacios de debate constitucional por lo que, si es que se aprueba una nueva Constitución, es probable que tiendan a diluirse.

Por supuesto, esto último es especulación, pero lo que no es especulación, pienso, es que sin territorio no se puede construir autonomía, sin otra forma de hacer política no se puede prescindir de los partidos políticos, sin cuestionar al Estado y toda la institucionalidad no se terminarán los abusos de todo el modelo neoliberal. Eso lo entendieron los mapuche y, por eso, ahora la Coordinadora Arauco-Malleco (CAM) solidarizó con las justas demandas sociales que "representan el justo y digno clamor de un pueblo oprimido por las políticas neoliberales que ya hizo crisis por la avaricia y la ambición de los poderosos"186. La solidaridad es para con el pueblo chileno en lucha, pero la declaración está dirigida a "nuestro Pueblo-Nación Mapuche", lo cual conlleva una lectura de la realidad política desde el territorio mapuche en confrontación con el Estado chileno. Más todavía, el anclaje solidario, pero desde la autonomía, se deja prístinamente establecido al explicitar que

en este mismo contexto, y tomando en consideración la lucha de nuestro Pueblo Mapuche, hacemos un llamamiento a dar continuidad con mayor fuerza a la disputa territorial y la resistencia en contra del poder burgués, como lo venimos haciendo hace más de dos décadas ${ }^{187}$.

En una línea argumentativa un tanto distinta, el historiador Fernando Pairican (2020, entrevista personal) sostiene que el Movimiento Mapuche se sumó a las demandas del pueblo chileno, pero con su propia agenda, agregando que "en Temuco no son los chilenos los que inician las movilizaciones, sino que fueron los mapuche y es por eso que caen las estatuas de los colonizadores... o sea en algún momento se sobrepasó el imaginariodel movimiento chileno". El Movimiento Mapuche es de luenga data y, sin lugar a dudas, el Movimiento Mapuche Autonomista — continuidad histórica del anterior, aunque con una erupción cualitativa en la década de los noventa- es más reciente, pero ambos son

179 https://www.mapuexpress.org/2019/10/21/cam-frente-al-estallido-chileno-contra-el-orden-establecido/ 180 Idem. 
abrumadoramente más antiguos que el movimiento chileno. Entonces, no es dable establecer escalas valóricas para medir grados de efectividad, profundidades estratégicas o tácticas, capacidades de liderazgos, avances o retrocesos, victorias o derrotas, narrativas, repertorio de acciones, demandas, simbologías, entre otras, sino más bien identificar - reiteramos - elementos que los vinculan movimentalmente, sea en posición o contraposición. En horizonte colectivo, constituyéndose como un nosotros movimental chileno, un sujeto diferente a los existentes anteriormente, sin partidos políticos, sin referentes que ya no representan a nadie, sean estos ideológicos, políticos o sociales formales, como sindicatos. Me refiero a un pueblo movilizado, gente movilizada, ciudadanos movilizados, individuos movilizados y territorios movilizados. En suma, un sujeto diferente en construcción, difícil de definir, que asumió demandas del Pueblo Mapuche tal vez sin claridad cabal o precisión absoluta de lo que pueda implicar, por ejemplo, la plurinacionalidad ola pluriculturalidad, pero, ¿pueden los expertos o cualquiera explicar conceptualmente lo qué significa esto también? Después de todo, las movilizaciones no son el lugar para ello, lo relevante es que en todas las marchas y manifestaciones a través del país flamearon la wenufoye y la wünelfe, las banderas mapuche, como una forma de solidarizar con el Pueblo Mapuche, su lucha y, especialmente, su dignidad y coraje.

\section{Batalla de símbolos y algo más}

Los movimientos sociales se desplazan en distintas esferas para otorgarle sentido y orientación a su accionar; es la subjetividad hecha política, son los relatos, los mitos, los ritos, los cánticos, los rayados, las consignas, los colores, las memorias, las palabras y la identificación con la otredad. La batalla de los símbolos es otra manifestación de la confrontación por el poder entre la calle y el Estado que el Movimiento Mapuche inició, al menos, desde el año 1992 cuando el Consejo de Todas las Tierras (CTT) ${ }^{188}$ impulsó la creación de la wenufoye. Indica Jorge Weke, su creador final, que luego de un amplio proceso de consulta a las comunidades de las distintas identidades territoriales del Wallmapu, se elaboró esta bandera como "un símbolo de liberación, de auto reconocimiento como nación milenaria", agregando que "los mapuche no podemos honrar la bandera chilena, no podemos honrar símbolos con los cuales se han dado golpes de genocidio contra nuestra gente, todo ello en nombre de la patria"189. Entonces, el océano de exclusiones simbólicas del Estado-Nación para con los mapuche, por ejemplo, mediante los emblemas nacionales chilenos representativos de un Estado uninacional y unicultural, eran ahora interpelados y subvertidos por una bandera mapuche. Pronto esta se convertiría en un componente más, no solo de una batalla de significados, sino que de disputa en todos los ámbitos, porque la primera vez que se presentó en público en octubre de 1992, la manifestación fue violentamente reprimida por la policía. Eso no es simbólico, sino material. No es intangible, sino tangible, como lo es la militarización de la represión al movimiento social chileno, el que ha utilizado ampliamente la wenufoye y, también, la wünelfe, de campo azul y estrella blanca

181 Una de las más importantes organizaciones mapuche surgidas en la década del noventa, la primera que comenzó la elaboración de un discurso de libre determinación, de reconocimiento de derechos colectivos y de reestructuración de la organización social ancestral con sus autoridades propias. Además, planteaba la desafiliación de los partidos políticos chilenos.

182 https://sites.google.com/site/delospueblosindigenas/la-bandera-mapuche-contada-por-jorge-weke 
de ocho puntas. Emblemas de resistencia y dignidad que podrían reflejar lo mencionado anteriormente, es decir, el surgimiento de un nuevo sujeto social que, cansado de añosos y desprestigiados actores políticos, se halla en la búsqueda de otros. No sugerimos que el movimiento social chileno define al Movimiento Mapuche, a través del uso masivo de sus emblemas, como un conductor político, sino, simplemente, que lo visualiza como un actor colectivo de dignidad. "Ante la orfandad de referentes, de símbolos e incluso de utopías ideológicas a seguir, aparece la larga y centenaria lucha mapuche como un espejo donde los chilenos y chilenas buscan su reflejo" (Cayuqueo, 2020, entrevista personal).

La Primera Línea ${ }^{190}$, un fenómeno socio-político de acción directa que desempeña un papel extraordinario de autodefensa de masas, es parte integral de esta conflagración simbólica, pero también material, toda vez que numerosos de sus escudos, vestimentas, cascos u otros elementos de protección portan símbolos mapuche. Muchos de los jóvenes de la Primera Línea son mapuche. No es sólo la Primera Línea, son todas las líneas, un entrelazamiento de líneas horizontales y verticales, espaciales y temporales, porque

el movimiento social chileno transversalmente se ha permeado de contenido simbólico indígena.

Las banderas representativas de los pueblos indígenas (wenufoye, WIPALA, rapanui), las actitudes, estéticas e iconos que acompañan las defensas de los territorios, son culturas de resistencia que se traspasan, se apropian, circulan como aprendizajes fecundos de lucha que sabemos cuándo estallaron, aunque no vislumbramos su culminación ${ }^{191}$. (Comunidad de Historia Mapuche CHM)

Dichas culturas de resistencia pudieron haber tenido mayores o menores grados de planificación, espontaneidad o grados de conciencia política o histórica. Lo relevante, desde el análisis general de la relación movimental desde abajo, es que se constata una práctica donde lo chileno y lo mapuche se encuentran. Para los mapuche, la wenufoye es un signo descolonizador, para los chilenos constituye un símbolo de solidaridad con la lucha del Pueblo Mapuche pero, simultáneamente, un cuestionamiento al nacionalismo vacío, a un país desigual, a un Chile que solo le pertenece a una élite. A un Estado que ha construido una historia oficial y ha ocultado la del pueblo, ese pueblo que ahora está en la calle. El mismo Estado que moldeó esa historia en colosales monumentos de piedra o bronce y los clavó en territorio mapuche para que nadie olvidara que los indígenas no tenían derecho a vivir en su propia tierra. Pero estos sobrevivieron y vivieron agenciando no solamente derechos étnicos individuales, sino que colectivos, como pueblos.

En una masiva marcha, el 29 de octubre derribaron la estatua de Pedro de Valdivia en la calle Balmaceda en Temuco. Mas esta furia de siglos no es contra los españoles exclusivamente, sino que contra el Estado chileno que es el principal responsable de la guerra contra los mapuche y del actual conflicto. Por esto es que la des-monumentalización de la memoria histórica colonial

183 Grupo de auto-defensa de masas surgido al alero del Estallido Social, compuesto fundamentalmente por jóvenes que se enfrentan a la policía para defender a los manifestantes de la acción policial. Ha sido violentamente reprimido por Carabineros.

184 https://www.comunidadhistoriamapuche.cl/posicionamiento-del-centro-de-estudios-e-investigacion-mapuche-comunidadde-historia-mapuche-ante-el-proceso-politico-abierto-y-en-curso-en-el-wallmapu-y-chile/ 
(Huinca, 2019) no acabó con la dominación hispana, sino que con el colonialismo interno también, por aquel ejercido desde el poder chileno.

En este contexto, uno de los principales artífices de la ocupación militar de La Araucanía en el siglo XIX fue el coronel Cornelio Saavedra. El derribo de su busto en la plaza de la ciudad de Collipulli es, para los mapuche, una acción de justicia descolonizadora, una manera de re-escribir otra historia. Contarle a todo el mundo que esto no es vandalismo, que no es violencia, que violencia es lo que propulsó a Saavedra al decir que a los mapuche había que "quemar(les) sus ranchos, tomarles sus familias, arrebatarles sus ganados y destruir en una palabra todo lo que no se les puede quitar" (Saavedra, 2009: 211). Así, la des-monumentalización acontecida en todo el país es otro punto que hilvana a los movimientos desde el contra poder, aunque pueda haber especificidades históricas, territoriales, identitarias y culturales.

En Valparaíso se reapropió la estatua de Carlos Condell ${ }^{192}$, para rebautizar la Plaza Aníbal Pinto como Plaza de La Resistencia, en Punta Arenas se destruyó la estatua de José Menéndez, colono quien, con la anuencia del Estado chileno, dirigió la masacre del pueblo Selk'nam para instalar su empresa ganadera en la Patagonia. La inhumanidad del modelo económico, de la historia que no se nombra, que la des-monumentalización trata de narrar a pulso y sin permiso.

Sin permiso fueron también las decenas de marchas que hubo en Chile y Wallmapu con ocasión de la conmemoración de un año del asesinato de Camilo Catrillanca, siendo la de Temuco una de las más masivas. En la comunidad de Temucuicui, donde vivía Camilo y su familia, se realizó una ceremonia especial. Una ceremonia pacífica como las movilizaciones, las cuales indistintamente fueron reprimidas por Carabineros. Por supuesto que ello responde a un patrón y a una estrategia diseñada por La Moneda desde el comienzo del Estallido, por tanto, no constituye novedad. Lo grave es que los responsables y ejecutores directos de instruir a la policía para reprimir a los manifestantes, son los mismos responsables políticos del asesinato de Camilo Catrillanca. La mantención del orden público es nada más que la mantención del control social, o sea, del sistema total y, en este marco, la legalidad y la justicia no son equivalentes. Andrés Chadwick, ex ministro del Interior, tenía el mismo cargo al momento de la muerte y encubrimiento del crimen de Catrillanca, al igual que el ex subsecretario Rodrigo Ubilla. Los dos encargados de las fuerzas policiales ese 14 de noviembre - otro noviembre maldito- reprimieron las actividades de conmemoración del crimen que ellos habían encubierto en primera instancia. Ninguno de los dos asumió su responsabilidad política, sin importar las conclusiones de la Comisión Investigadora de la Cámara de Diputados que sí lo hizo porque, como declaró su presidente, el diputado del partido por la democracia PPD, Raúl Celis, "ésta es una de las violaciones más flagrantes y graves a los derechos humanos que se hayan realizado en este último tiempo contra una persona, y un comunero en particular ${ }^{193}$ ". Empero, el ministro del Interior prosiguió transgrediendo severamente la Constitución y las leyes, permitiendo la sistemática violación a los derechos humanos. Producto de todo ello fue la aprobación por

185 Uno de los héroes de la Guerra del Pacifico de acuerdo a la historiografía oficial.

186 https://www.eldesconcierto.cl/2019/09/12/caso-catrillanca-informe-final-de-comision-investigadora-estableceresponsabilidad el senado -politica-de-chadwick-y-ubilla/ 
el Senado de la acusación constitucional en diciembre de 2019. El destituido ministro, no obstante, manifestó "condenar con toda mi energía y convicción, todo acto de violencia, ya sea contra una

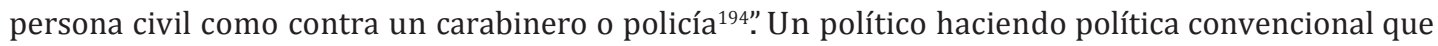
tanto lo ha deslegitimado, a pesar de los 450 chilenos y chilenas a quienes se les han arrancado su vista, los miles de detenidos, torturados y gaseados. Las ciudades y pueblos en Estado de Emergencia, con militares en las calles como en las oscuras épocas de la dictadura. Todo, con su autorización, porque el Gobierno le declaró la guerra al pueblo, tal como al principio, cuando se bosquejaba la nación chilena, se le declaró la guerra a muerte al Pueblo Mapuche.

Pero el Pueblo Mapuche se niega a morir y estoy convencido de que el movimiento del Estallido también. Los mapuche necesitan tierra y se las siguen quitando. El mismísimo ex subsecretario Rodrigo Ubilla fue procesado el 2019 por la compra irregular de tierras indígenas en la comuna de Pucón en la Región de La Araucanía. Adquirió, por la suma de 10 millones de pesos, 2 predios en la comunidad Mariano Millahual de Pucón. El Juzgado de Letras de Pucón impugnó el traspaso de la propiedad, ubicada al interior de la comunidad, puesto que la compraventa fue ilegal, tal como establece la Ley Indígena, pues estas deben hacerse entre indígenas. ¿Por qué lo hizo entonces? ¿Desconocía la Ley? Quizás es la soberbia actitud racista decimonónica que otorga el derecho a la élite a hacer lo que se desee con los indígenas (Tricot, 2013).

En pleno Estallido y movimiento social, el mismo Ubilla hubo de renunciar, aduciendo razones personales, pero él tenía a su cargo la coordinación operativa de Carabineros y la responsabilidad de la seguridad y el orden público. 0 sea, fue directamente responsable de todas las violaciones a los derechos humanos consignados en, al menos, cuatro informes nacionales e internaciones. Además, debe adicionarse la irregular compra de tierras mapuche y el encubrimiento del asesinato de Camilo Catrillanca en el sur. Ubilla es la violencia racionalizada en un hombre, pero no es el hombre, pues vendrán otros. Es el sistema, el panóptico, el gran ojo que vigila para arrancar todos aquellos ojos que le molesten. Y una de las cuestiones que más les molesta es el potencial cambio de Constitución.

\section{La posibilidad de una Constitución plurinacional y pluricultural}

Una de las grandes demandas del movimiento derivado del Estallido es una nueva Constitución y, por consiguiente, el rechazo a la Constitución dictatorial, mantenida por 30 años por los gobiernos que le sucedieron. Los cabildos, asambleas territoriales, movilizaciones y múltiples actividades, centraron su atención en el tema constitucional. No fue el único tema, pero sí uno importante. Una de las demandas del movimiento social y de un segmento significativo del Movimiento Mapuche es por una nueva Constitución. Más concretamente, una de carácter plurinacional y pluricultural. La interrogante que asoma inmediatamente, por supuesto, es si esto será posible con la existencia de un Estado férreamente nacionalista racista y unitario. Para Antileo (2020, entrevista personal) "es vital pensarse como un país conformado por colectivos históricos diversos, como un país plu-

187 https://www.diarioconcepcion.cl/politica/2019/12/11/aprobada-la-acusacion-constitucional-chadwick-es-sancionado- por-su-rolen-violaciones-de-ddhh.html 
rinacional". El movimiento social ha incorporado demandas de los pueblos originarios, no solo simbólicas, sino que políticas - y muy concretas - como aquella de un Estado plurinacional como parte de un proceso constituyente. "Estamos en un momento donde es posible. Estamos a un paso,

puede ser una gran victoria o una derrota”. Es que, precisamente, hoy nadie podría considerar

legítima una nueva Constitución escrita a espaldas de nuestros pueblos o sin nuestra participación directa. Este escenario, inédi to en la historia de este país, es fruto de una larga lucha y de los puentes que muchos dirigentes y dirigentas han tendido con los sectores conscientes de la sociedad chilena. (Cayuqueo, 2020, entrevista personal)

La Asociación de Municipalidades con Alcaldes Mapuche (AMCAM), por ejemplo, posee experiencias de plurinacionalidad en la práctica y, simultáneamente, busca construir un Estado plurinacional e intercultural que garantice sus derechos colectivos en la perspecti va de la autonomía. No obstante, para otros mapuche, como Aukan Huilcaman, werken ${ }^{195}$ del CTT, la plurinacionalidad consistiría en la domesticación de los derechos colectivos en tanto pueblo, una nueva forma de colonización. Tanto así que realizó un trawün ${ }^{196}$ en el Cerro Ñielol de Temuco expresando su voluntad de avanzar hacia la creación de un gobierno independiente en el territorio mapuche. Para la CAM, un Estado plurinacional es una contradicción puesto que el Estado es un ordenamiento socio-político moderno y ellos están por la reestructuración de su institucionalidad mapuche (Llaitul, 2016, entrevista personal). Por su lado, Pairican (2020, entrevista personal), visualiza la "plurinacionalidad como un proceso de inicio hacia la descolonización, un camino hacia la interculturalidad al nivel del quehacer político. No es la domesticación ni la imposibilidad de la autodeterminación." Va más allá, señalando que, si bien es efectivo que existe el apoyo del movimiento social a los mapuche y a que estos sean parte de la Constitución, encuestas recientes señalan que los chilenos parecieran confundir lo que es plurinacionalidad y multiculturalidad. Es decir, apoyan que los mapuche o pueblos originarios sean parte del Estado, tengan derechos, pero no que tengan autonomía.

Si será o no plurinacional y pluricultural el Estado chileno, es imposible de determinar, particularmente después de la firma del Acuerdo por la Paz y una nueva Constitución, el 15 de noviembre de 2019, otro noviembre de la Primavera nuestra de cada noche. Aquí comienza el periplo racista y colonizante, donde se recurre a todos los artificios legales y políticos para excluir a los pueblos originarios de la Convención Constitucional. La Asamblea Constituyente, exigida por el movimiento social, ya se había descartado por la clase política. En definitiva, el debate de la participación indígena y el probable número de escaños asignados es un problema para la clase política. Discusión que, luego de haber pasado por distintos trámites en su maremágnum legislativo, se halla ahora en la incertidumbre política.

Nadie sabe qué sucederá. ¿Terminará en un fracaso el asunto de la participación de los pueblos originarios en la convención mediante escaños reservados? ¿Será un fiasco como la Consulta Indígena que acaba de colapsar o como las decenas de mesas de diálogo que jamás llegan a algo, básicamente porque nunca toman en consideración las demandas de

\footnotetext{
188 Vocero

189 Encuentro mapuche.
} 
los pueblos originarios? Es que transformar el Estado uninacional y unicultural por uno plurinacional y pluricultural, que tenga la voluntad y capacidad de reconocer que en este país que llamamos Chile no todos somos chilenos, requiere un esfuerzo movimental colosal. Puede que se escriba una nueva Constitución que no cambie absolutamente nada y una Constitución que no sea ni plurinacional ni pluricultural. Es la incertidumbre total, como el COVID-19, que nos golpea mundialmente. Lo que sí está meridianamente claro es que sin el Movimiento Mapuche Autonomista jamás se hubiese hablado de plurinacionalidad y pluriculturalidad y, también que, sin el Estallido, tampoco se hubiera hablado del cambio de Constitución como una realidad posible.

\section{Conclusiones}

La vinculación de la denominada Primavera Chilena y el Movimiento Mapuche es de carácter diverso y, por el mismo carácter singular de cada uno de los movimientos, pletórico en especificidades. La novedad del Estallido y lo embrionario del movimiento social que devino de aquel, contrasta evidentemente con la madurez histórica del Movimiento Mapuche. Sin embargo, fue posible identificar, en el marco general de las dimensiones de poder y contra-poder, ciertos elementos que permitieron establecer símiles y diferencias en narrativas, simbologías, acciones, liderazgos, construcción de sujetos y elaboración de estrategias, entre otros. La identificación y edificación de poder desde abajo es una interesante constatación. Por otro lado, la conexión desde arriba, desde el poder, por medio de la violencia, constituye una confirmación dramática de que el modelo y el sistema, en su conjunto, son una estructura coercitiva, donde la violencia actúa como un mecanismo más para su preservación, dónde y cuándo se requiera. En este sentido, no existen ni consideraciones ni fronteras étnicas, nacionales, culturales o de género.

El Estallido y el movimiento social chileno tienen, sin duda, relación con el Movimiento Mapuche en las esferas simbólicas y prácticas, en lo tangible e intangible, en su cuestionamiento al Estado-Nación, al modelo neoliberal, a la política y los políticos. Esto los une como el hecho de convivir en un territorio que puede plurinacionalizarse y pluriculturalizarse. 


\section{Bibliografía}

CÁMARA DE DIPUTADAS Y DIPUTADOS. (12 de Septiembre de 2019). Aprueban informe que asigna responsabilidades a Carabineros y al Gobierno por caso Catrillanca. Obtenido de Cámara de Diputadas

Diputados:

https://www.camara.cl/prensa/sala_de_prensa_detalle.aspx?prmid=137968

CHM. (29 de Noviembre de 2019). Posicionamiento del Centro de Estudios e Investigación Mapuche Comunidad de Historia Mapuche. Ante el proceso político abierto y en curso en el Wallmapu y Chile. Obtenido de Comunidad de Historia Mapuche: https://www. comunidadhistoriamapuche.cl/posicionamiento-del-centro-de-estudios-e-investi-gacionmapuche-comunidad-de-historia-mapuche-ante-el-proceso-politico-abier- to-y-en-cursoen-el-wallmapu-y-chile

CLAUSEWITZ, K. v. (2002). “De la guerra”. Librodot.com

COORDINADORA ARAUCO MALLECO. (21 de Octubre de 2019). CAM frente al estallido chileno contra el orden establecido. Obtenido de Mapuexpress: https://www.mapuexpress.org/2019/10/21/cam-frente-al-estallido-chileno-contra-el-orden-establecido/

EL DESCONCIERTO. (22 de Febrero de 2019). Piñera insiste en que hay «terrorismo» en La Araucanía «Los que lo quieran negar están tratando de tapar el sol con un dedo». Obteni- do de El Desconcierto : $\quad$ https://www.eldesconcierto.cl/2019/02/21/pinera-insiste-en- que-hay-terrorismo-en-laaraucania-los-que-lo-quieran-negar-estan-tratando-de-ta- par-el-sol-con-un-dedo/

EL MOSTRADOR. (01 de Octubre de 2019). Chadwick no descarta aplicar Estado de Excepción en La Araucanía. Obtenido de El Mostrador: https://www.elmostrador.cl/noticias/ pais/2019/01/10/chadwick-no-descarta-aplicar-estado-de-excepcion-en-la-arauca- nia/

GARCÉS, M. (2019). "Rebelión popular y proceso constituyente en Chile”, en FOLCHI Mauricio (Ed), Chile Despertó, Lecturas desde la Historia del Estallido Social de Octubre. Santiago de Chile, Universidad de Chile.

GUERRERO, M. (2006). "El conjuro de los movimientos sociales en el Chile neoliberal”, Revista venezolana de Economía y Ciencias Sociales, mayo-agosto 2006, Vol.12, № 002, Universidad Central de Venezuela, Venezuela, 2006.

NAMUNCURA, D., et al. (2016). Nueva Constitución y Pueblos Indígenas. Pehuén Editores, S.A., Santiago de Chile.

RUIZ, C. (2020). Octubre chileno, la irrupción de un nuevo pueblo. Taurus, Santiago de Chile. SAAVEDRA, C. (2009). Documentos relativos a la ocupación de Arauco. Cámara Chilena de la 
Construcción, Pontificia Universidad Católica de Chile, Dirección de Bibliotecas Archivos y Museos, Santiago de Chile.

TAURAN, E. (11 de Diciembre de 2019). Aprobada la acusación constitucional: Chadwick es sancionado por su rol en violaciones de DD.HH. Obtenido de Diario Concepción: https:// www.diarioconcepcion.cl/politica/2019/12/11/aprobada-la-acusacion-constitucio-nalchadwick-es-sancionado-por-su-rol-en-violaciones-de-ddhh.html

TRICOT, T. (2017). Aukan. Violencia histórica chilena y contraviolencia mapuche. Editorial Ceibo, Santiago de Chile.

(2013) Autonomía Mapuche de resistencia. Editorial Ceibo, Santiago de Chile.

TRICOT, V. y BIDEGAIN, G. (2020). "En busca de la representación política: el partido mapuche

Wallmapuwen en Chile”. Estudios Sociológicos, 38(113), mayo-agosto, 2020.

WEKE, J. (13 de Mayo de 2010). La bandera mapuche contada por Jorge Weke . (P. Cayuqueo, Entrevistador)

\section{Entrevistas}

Pedro Cayuqueo, periodista mapuche. Mayo 2020. Fernando Pairican, historiador mapuche. Mayo 2020. Enrique Antileo, antropólogo mapuche. Mayo 2020. 


\section{Otras Fuentes}

Informe de la Misión a Chile Comisión del Alto Comisionado para los Derechos Humanos de las Naciones Unidas 30 octubre-22 noviembre 2019.

República de Chile, Diario de sesiones del Senado. Publicación oficial, Legislatura 366 a Sesión 76aㅡ, miércoles 12 de diciembre de 2018.

Medios consultados Eldesconcierto.cl Mapuexpress.cl Biobio.cl Elmostrador.cl Cooperativa.cl Eldinamo.cl Latercera.cl

Emol.cl Diarioconcepcion.cl Senado.cl

\section{Cronología}

\begin{tabular}{|c|c|c|}
\hline Fecha & Acontecimiento & Descripción \\
\hline $\begin{array}{l}14 \text { de noviembre de } \\
2018\end{array}$ & $\begin{array}{l}\text { Asesinato } \\
\text { mapuche } \\
\text { Catrillanca }\end{array}$ & $\begin{array}{l}\text { Carabineros asesina en la comunidad de } \\
\text { Temucuicui al joven Catrillanca por la espalda. } \\
\text { Acusa que iba armado. Se descubre que era un } \\
\text { montaje, el cual fue avalado y respaldado } \\
\text { inicialmente por el Gobierno. }\end{array}$ \\
\hline $\begin{array}{l}12 \text { de diciembre de } \\
2018\end{array}$ & $\begin{array}{l}\text { Sesión Especial del } \\
\text { senado sobre situación en } \\
\text { LaAraucanía }\end{array}$ & $\begin{array}{l}\text { Se discute la situación en la región, } \\
\text { incluyendo la muerte del comunero Camilo } \\
\text { Catrillanca. Participan el ministro Andrés } \\
\text { Chadwick y el ministro de Desarrollo Social, } \\
\text { Alfredo Moreno. }\end{array}$ \\
\hline $\begin{array}{l}10 \text { de enero de } \\
2019\end{array}$ & $\begin{array}{l}\text { Andrés Chadwick, } \\
\text { ministro del Interior visita } \\
\text { la Región de La Araucanía }\end{array}$ & $\begin{array}{l}\text { A tan solo dos meses del asesinato de Camilo } \\
\text { Catrillanca, no descarta declarar Estado de } \\
\text { Emergencia en la región. Se reúne con con } \\
\text { agricultores de la zona. No se reúne con } \\
\text { familiares de Camilo Catrillanca. }\end{array}$ \\
\hline $\begin{array}{l}21 \text { de febrero } \\
\text { de } 2019\end{array}$ & $\begin{array}{l}\text { Presidente Piñera visita } \\
\text { La Araucanía }\end{array}$ & $\begin{array}{l}\text { Presidente Piñera visita la región, para } \\
\text { inaugurar una comisaría, dar respaldo a } \\
\text { Carabineros y reiterar que existe terrorismo } \\
\text { en la zona. }\end{array}$ \\
\hline $\begin{array}{l}02 \text { de junio } \\
\text { de } 2019\end{array}$ & $\begin{array}{l}\text { Autoridades y dirigentes } \\
\text { mapuche se reúnen con } \\
\text { diputados en Valparaíso }\end{array}$ & $\begin{array}{l}\text { En el marco del asesinato de Camilo } \\
\text { Catrillanca, un centenar de autoridades y } \\
\text { dirigentes de diferentes comunidades } \\
\text { presentan su posición y demandas ante sesión } \\
\text { especial de la Cámara de diputados. }\end{array}$ \\
\hline $\begin{array}{l}18 \text { de octubre de } \\
2019\end{array}$ & Comienza Estallido Social & $\begin{array}{l}\text { Con el salto de torniquetes del Metro de } \\
\text { Santiago por un grupo de estudiantes } \\
\text { secundarios, comienza simbólica y } \\
\text { factualmente el mayor movimiento social de } \\
\text { las últimas décadas en Chile. }\end{array}$ \\
\hline
\end{tabular}




\begin{tabular}{|c|c|c|}
\hline Fecha & Acontecimiento & Descripción \\
\hline $\begin{array}{l}29 \text { de octubre de } \\
2019\end{array}$ & $\begin{array}{l}\text { Se derriba estatua de Pedro de } \\
\text { Valdivia en Temuco }\end{array}$ & $\begin{array}{l}\text { Manifestación de mapuche que se } \\
\text { encontraban en las afueras de la cárcel } \\
\text { de Temuco donde manifestaban su } \\
\text { apoyo a los presos políticos mapuche, } \\
\text { derribaron la estatua del conquistador } \\
\text { Pedro de Valdivia. }\end{array}$ \\
\hline $\begin{array}{l}29 \text { de octubre de } \\
2019\end{array}$ & $\begin{array}{l}\text { Derribo de busto de Cornelio } \\
\text { Saavedra en Collipulli }\end{array}$ & $\begin{array}{l}\text { Se descuelga de su pedestal busto de } \\
\text { Cornelio Saavedra, el principal } \\
\text { responsable de la ocupación militar de } \\
\text { terri torio mapuche en el siglo XIX. }\end{array}$ \\
\hline $\begin{array}{l}09 \text { de noviembre } \\
\text { de } 2019\end{array}$ & $\begin{array}{l}\text { Comunidades mapuche } \\
\text { anuncian instalación de nuevo } \\
\text { Gobierno independiente en } \\
\text { territorio mapuche }\end{array}$ & $\begin{array}{l}\text { Aukan Huilcaman, werken del Consejo } \\
\text { de Todas las Tierras, se reúne en } \\
\text { Temuco con } 250 \text { comunidades y } \\
\text { aprueban creación de gobierno } \\
\text { independiente mapuche desde el Biobío } \\
\text { al sur. }\end{array}$ \\
\hline $\begin{array}{l}03 \text { de noviembre } \\
\text { de } 2019\end{array}$ & 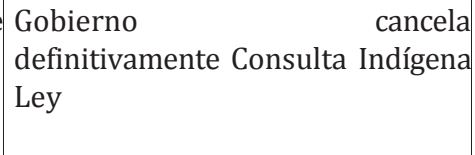 & $\begin{array}{l}\text { Luego de anteriores suspensiones } \\
\text { producto de irregulares procedimientos } \\
\text { y protestas de los mismos indígenas, se } \\
\text { cancela definitivamente la consulta. }\end{array}$ \\
\hline $\begin{array}{l}03 \text { de noviembre } \\
\text { de } 2019\end{array}$ & \begin{tabular}{|llll} 
Participación & \multicolumn{2}{c}{ de alcaldes } \\
mapuche en & comisión & de \\
constitución & de & Cámara & de \\
Diputados & & &
\end{tabular} & $\begin{array}{l}\text { Alcaldes mapuche exigen escaños } \\
\text { reservados en la Convención } \\
\text { Constituyente. }\end{array}$ \\
\hline $\begin{array}{l}14 \text { de noviembr } \\
\text { de } 2019\end{array}$ & $\begin{array}{l}\text { Conmemoración de } 1 \text { año del } \\
\text { asesinato del comunero mapuche } \\
\text { Camilo Catrillanca }\end{array}$ & $\begin{array}{l}\text { Se realizan al menos } 35 \\
\text { manifestaciones en todo el país para } \\
\text { conmemorar su muerte. La más grande } \\
\text { se realiza en Temuco. }\end{array}$ \\
\hline $\begin{array}{l}15 \text { de noviembr } \\
\text { de } 2019\end{array}$ & $\begin{array}{l}\text { Acuerdo por la Paz Social y } \\
\text { Nueva Constitución }\end{array}$ & $\begin{array}{l}\text { Este acuerdo fue firmado por todos los } \\
\text { partidos políticos y la oposición, } \\
\text { excepto el partido comunista y } \\
\text { humanista. De aquí emana la } \\
\text { posibilidad elaborar una nueva } \\
\text { Constitución y, quizás, escaños } \\
\text { reservados para pueblos originarios. }\end{array}$ \\
\hline $\begin{array}{l}11 \text { de diciembre de } \\
2019\end{array}$ & $\begin{array}{l}\text { Se aprueba acusación } \\
\text { constitucional contra ministro } \\
\text { Andrés Chadwick }\end{array}$ & $\begin{array}{l}\text { El Senado aprueba la acusación contra } \\
\text { el ministro por haber infringido } \\
\text { gravemente la Constitución y las leyes, } \\
\text { y haber dejado de adoptar medidas } \\
\text { para detener violaciones sistemáticas a } \\
\text { los derechos humanos. Además, por }\end{array}$ \\
\hline
\end{tabular}




\begin{tabular}{|l|l|l|}
\hline & & $\begin{array}{l}\text { haber “comprometido gravemente el } \\
\text { honory y la seguridad de la Nación”. }\end{array}$ \\
\hline $\begin{array}{l}16 \text { de diciembre de } \\
2019\end{array}$ & $\begin{array}{l}\text { Renuncia del subsecretario del } \\
\text { interior Rodrigo Ubilla }\end{array}$ & $\begin{array}{l}\text { La renuncia, según Ubilla, obedece a } \\
\text { razones personales. Sin embargo, su } \\
\text { participación en las violaciones a los } \\
\text { derechos humanos y a las ilegales } \\
\text { compras de tierras indígenas (por lo } \\
\text { que fue condenado por el Juzgado de } \\
\text { Letras de Pucón) debe haber influido en } \\
\text { su decisión. }\end{array}$ \\
\hline
\end{tabular}

